\title{
Prosthesis-patient mismatch and clinical outcomes: The evidence continues to accumulate
}

\author{
Jean G. Dumesnil, MD, FRCP (C), FACC, and Philippe Pibarot, DVM, PhD, FACC
}

See related article on page 1036 .

From the Québec Heart Institute, Lava Hospital, Sainte-Foy, Quebec, Canada.

Received for publication Nov 21, 2005; revisions received Dec 13, 2005; accepted for publication Dec 16, 2005.

Address for reprints: Jean G. Dumesnil, Québec Heart Institute, Laval Hospital, 2725 Chemin Sainte-Foy, Sainte-Foy, Quebec, Canada G1V-4G5 (E-mail: medjgd@ hemes.ulaval.ca).

J Thorac Cardiovasc Surg 2006;131:952-5

$0022-5223 / \$ 32.00$

Copyright (๑) 2006 by The American Association for Thoracic Surgery

doi:10.1016/j.jtcvs.2005.12.032
T $\mathrm{n}$ this issue of the Journal, Ruel and associates ${ }^{1}$ report that aortic valve prosthesis-patient mismatch (PPM) predominantly affects patients with left ventricular (LV) dysfunction. As they point out, PPM remains a controversial issue. On the one hand, there is indeed an increasing body of evidence suggesting that PPM occurs frequently and has important clinical consequences. ${ }^{2-13}$ To the opposite, some authors have argued that PPM is a rare phenomenon without relevant clinical implications. ${ }^{14-19}$ The article from Ruel and colleagues ${ }^{1}$ brings new evidence from two standpoints: (1) It further documents the impact of PPM on long-term clinical outcomes such as survival, freedom from heart failure, and LV mass regression, whereas there has been a paucity of data in this regard and most studies have been limited to the short or medium term; (2) it adds a new dimension to this type of study in that it examines whether PPM and preoperative LV function interact with regard to their impact on these outcomes.

\section{Definition of PPM}

Given the controversy that has surrounded PPM and to put the findings of Ruel and coworkers into proper perspective, it is important to review certain essential elements regarding this concept and its identification. Indeed, the term PPM was first coined in 1978 by Rahimtoola, ${ }^{20}$ who defined it as follows: "Mismatch can be considered to be present when the effective prosthetic valve area, after insertion into the patient, is less than that of a normal human valve." In his original publication, the author insisted that the main consequence of PPM would be to produce higher postoperative gradients resulting in an increased hemodynamic burden for the ventricle, and he actually provided a graph summarizing his vision of the relation between the effective orifice area (EOA) of the prosthesis and postoperative gradients. However, the graph showed no normalization for body size and, as it stood, it could be interpreted as the conceptual relation that would exist between EOA and gradients in a person with average body size. Importantly, it must be emphasized that higher postoperative gradients and increased LV workload are inherent to the concept of PPM. Hence, an alternate definition for PPM could well be: "PPM occurs when the EOA of the prosthesis is too small in relation to the patient's body size, resulting in abnormally high postoperative gradients."

\section{Parameter Used to Define PPM}

The parameter first proposed to identify PPM has been the indexed EOA, which is the EOA of the prosthesis divided by the patient's body surface area. ${ }^{21,22}$ It should be emphasized that the EOA is a physiologic parameter derived from hydraulic principles and it corresponds to the area occupied by flow as it exits the valve. Clinically, it is calculated from either the continuity equation when using echocardiography or the Gorlin formula during cardiac catheterization. Unfortunately, it cannot be predicted from the size of the prosthesis or its geometric area because the criteria used to calculate the geometric area vary from one type of prosthesis to the other; in addition, the ratio between the EOA and the geometric area also varies widely from one type and/or size of prosthesis to another. ${ }^{8,14,23}$ The rationale behind the normalization of the EOA for body surface area is to account for cardiac output requirements since transvalvular pressure gradients are essentially determined by the EOA and transvalvular flow, which in turn are largely determined by body size. 


\section{Abbreviations and Acronyms \\ EOA = effective orifice area (physiologic parameter derived from hydraulic principles and corresponding to the actual area occupied by flow as it exits the valve; directly related to hemodynamics and gradients) \\ $\mathrm{GOA}=$ geometric orifice area (alternate term used to describe the IGA) \\ IGA $=$ internal geometric area (anatomic area of the prosthesis at inflow, calculated from the static measurement of the inner diameter of the prosthesis at that level; no relation to hemodynamics and gradients) \\ IOA = indexed orifice area (alternate term used to identify the IGA indexed for body surface area; can be misleading since does not specify whether this is geometric or effective area and can thus be easily confounded with the EOA indexed for body surface area, which is an entirely different parameter) \\ $\mathrm{LV}=$ left ventricular \\ PPM = prosthesis-patient mismatch (occurs when the EOA of the prosthesis is too small in relation to the patient's body size, resulting in abnormally high postoperative gradients)}

Reference values for EOA data exist for each type and size of prosthesis, ${ }^{5,8}$ and they should ideally be derived from in vivo rather than in vitro values since the latter are often more optimistic than the former and are not representative of the real-life situation. To this effect, it should be emphasized that, as was done in this study, the indexed EOA calculated from such reference values or from postoperative echocardiograms remains the only parameter that has been successfully validated to predict postoperative outcomes, ${ }^{2-13}$ as well as to prospectively prevent $\mathrm{PPM}^{24}$ and avoid high postoperative gradients.

However, as is the case for many physiologic parameters, the EOA has some inherent variability that is mainly related to the techniques used for its measurement, as well as to a certain flow dependency. For this reason, some authors have alternatively attempted to characterize PPM in terms of the indexed internal geometric area (IGA) rather than the indexed EOA. ${ }^{14-16}$ In contrast to the EOA, the IGA is an anatomic parameter calculated from the static measurement of the internal diameter of the prosthesis. In this sense, it is very reproducible and exhibits little variability. However, it has consistently been shown to be unrelated to either postoperative gradients ${ }^{25}$ or clinical outcomes. ${ }^{14-19}$ This point is well illustrated by the recent data of Koch and associates, ${ }^{19}$ whereby these authors reported identical values for indexed IGA in patients with pericardial valves and patients with allografts whereas peak and mean gradients were twice as high in the former as in the latter. Not surprisingly, the same article found no relation between the indexed IGA and the clinical outcome of functional recovery after surgery. As appropriately pointed out by the authors, one of the likely explanations for the discrepancy between their results and other studies showing a relation between PPM and clinical outcomes is the difference in choice of parameters to identify PPM.

Hence, it becomes evident from a practical standpoint that, notwithstanding its limitations, the indexed EOA is the only parameter with proven validity to characterize PPM, prevent its occurrence, and predict postoperative outcomes. For this reason and to avoid further confusion, we would thus propose that the term $P P M$ be used only with regard to data collected by use of the indexed EOA, whereas data collected by use of the indexed IGA should be more appropriately termed prosthesis-patient size. These considerations also further emphasize that it is not the size or the geometric dimensions of a prosthesis that are clinically relevant, but rather the match between its anticipated hemodynamic performance and the size of the patient. When the right parameter is used for its identification, PPM is also found be to a relatively frequent phenomenon $^{5,8,12}$ akin to the $40 \%$ prevalence $(325 / 805$ patients) observed in the present study.

\section{Interaction Between PPM and LV Function}

To analyze how the relation between PPM and clinical outcomes might be affected by LV function is conceptually attractive since an increased hemodynamic burden should theoretically be less well tolerated by a poorly functioning ventricle than by a normal ventricle. ${ }^{26,27}$ In this sense, the present results are extremely valuable in that they indirectly corroborate the data of Blais and colleagues, ${ }^{8}$ showing a strong interaction between PPM and depressed LV function with regard to early mortality after AVR, and are the first to show that such an interaction also exists in relation to late mortality, heart failure, and LV mass regression.

An important limitation of the study, however, is that characterization of LV function was based only on a visual estimate of the ejection fraction by one or more of four blinded observers. Given that LV function is a major and pivotal variable of the study, it is indeed unfortunate that the authors did not provide some measure of intraobserver or interobserver variability and/or did not corroborate their results by the use of a more objective method of quantifying the ejection fraction. In this context, it becomes difficult to ascertain what might have been the margin of error and how many patients might have been misclassified. This limitation also has to be taken into consideration when analyzing the clinical implications of the study. 


\section{Threshold Values for Identification and Classification of PPM}

The threshold values of indexed EOA used to identify and classify PPM have also been a matter of discussion. ${ }^{10}$ In the present study, the authors have elected to dichotomize their patients between those having an indexed EOA below or above $0.85 \mathrm{~cm}^{2} / \mathrm{m}^{2}$, whereas other studies have used threshold values ranging from 0.75 to $0.90 \mathrm{~cm}^{2} / \mathrm{m}^{2}$ to dichotomize patients. An alternate approach has also been to consider PPM as a continuum rather than a dichotomy and, as is routinely done for native aortic valve disease, to classify patients according to the degree of severity. ${ }^{7,8,9,12}$ Indeed, when the latter approach is used, a strong relation can be found between the degree of severity of PPM and the prevalence of negative outcomes. For unknown reasons, the present study tested different thresholds of severity only in the case of LV mass and did indeed find significant differences. In the study of Blais and colleagues, ${ }^{8}$ the impact of PPM was found to increase exponentially in relation to the degree of severity to the extent that even patients with normal LV function were found to have a significant increase in early mortality when faced with severe PPM. Hence, one cannot exclude that a similar result might not have been observed in the present study had a similar type of analysis been performed. The appropriateness of classifying PPM according to the degree of severity is also corroborated by other studies ${ }^{7,9,12}$ and is logical in the sense that, as for native aortic valve disease, the impact of PPM should be viewed in relative terms, that is, in terms of the degree of imbalance between LV afterload and the status of LV function. ${ }^{27}$

\section{Clinical Implications}

The clinical implications of this study are important in that they clearly demonstrate that PPM has a significant impact on important clinical outcomes such as late survival, freedom from heart failure, and LV mass regression and that this impact is highly modulated by the functional status of the LV before surgery. The temptation to conclude from these findings that PPM is an important consideration only in patients with reduced LV function and can almost be dismissed as irrelevant in patients with normal LV function should, however, be avoided. Indeed, because PPM was analyzed as a dichotomy rather than a continuum, it cannot be excluded that severe PPM also had an impact in patients with normal LV function. Moreover, on examination of Figures 1 and 2 from Ruel's study, ${ }^{1}$ it is striking to see that patients with PPM and normal LV function tended to have poorer outcomes than those with no PPM and normal LV function, as well as those with no PPM and impaired LV function. Hence, the impact of PPM on clinical outcomes might well be at least as important as that of LV function. The fact that this did not come out in multivariate analysis might be due to the influence of other confounding variables. The issue is also further confounded by the potential variability in the estimate of the ejection fraction and the fact that patients with borderline values might have been misclassified. From a practical standpoint, to consider PPM irrelevant in a patient with normal LV function could be hazardous given that the eventual occurrence of severe PPM or misclassification of LV function cannot be excluded in the individual patient.

In this context, it should be emphasized that the projected indexed EOA of the prosthesis to be inserted can be calculated before surgery and that, in the case of an anticipated PPM, alternate procedures such as aortic root enlargement ${ }^{24}$ or insertion of a better performing valve substitute (eg, supraannular bioprostheses, ${ }^{28}$ stentless valves, ${ }^{29}$ newer generation mechanical valves, ${ }^{30,31}$ homografts, or the Ross operation $^{32}$ ) can be envisioned. ${ }^{5,8}$ Castro and coworkers ${ }^{24}$ have indeed demonstrated that such a strategy can be used successfully to prevent PPM, and most manufacturers now provide user-friendly charts allowing easy calculation of the projected indexed EOA within the operating room. In any given case, this information can easily be incorporated within the clinical decision-making process and used in view of the other pertinent clinical factors such as age, level of physical activity, status of LV function, and concomitant procedures. For instance, if one projects moderate PPM in an elderly patient with reduced physical activity and normal LV function, it might be estimated that the benefits of doing an alternate procedure to avoid PPM are outweighed by the inherent risks or disadvantages of doing such a procedure. On the other hand, the reverse could be true if severe PPM was projected in the same patient and/or if there was evidence of impaired LV function. In this context, the present results are further confirmation that the projected indexed EOA should routinely be calculated before aortic valve replacement and become an integral part of the clinical decision-making process. Finally, the observation that PPM has a significant impact on LV mass regression only in patients with impaired LV function is new and intriguing. It will require further validation and documentation with regard to physiopathology and potential clinical implications.

\section{References}

1. Ruel M, Al-Faleh H, Kulik A, Chan KL, Mesana TG, Burwash IG Prosthesis-patient mismatch after aortic valve replacement predominantly affects patients with pre-existing left ventricular dysfunction: impact on survival, freedom from heart failure, and left ventricular mass regression. J Thorac Cardiovasc Surg. 2006;131:xxx-x.

2. Pibarot P, Honos GN, Durand LG, Dumesnil JG. The effect of patientprosthesis mismatch on aortic bioprosthetic valve hemodynamic performance and patient clinical status. Can J Cardiol. 1996;12:379-87.

3. Pibarot P, Dumesnil JG, Lemieux M, Cartier P, Métras J, Durand LG. Impact of prosthesis-patient mismatch on hemodynamic and symptomatic status, morbidity, and mortality after aortic valve replacement with a bioprosthetic heart valve. J Heart Valve Dis. 1998;7:211-8. 
4. Del Rizzo DF, Abdoh A, Cartier P, Doty DB, Westaby S. Factors affecting left ventricular mass regression after aortic valve replacement with stentless valves. Semin Thorac Cardiovasc Surg. 1999;11:114-20.

5. Pibarot P, Dumesnil JG. Hemodynamic and clinical impact of prosthesis-patient mismatch in the aortic valve position and its prevention. J Am Coll Cardiol. 2000;36:1131-41.

6. Rao V, Jamieson WRE, Ivanov J, Armstrong S, David TE. Prosthesispatient mismatch affects survival following aortic valve replacement. Circulation. 2000;102(suppl III):III5-9.

7. Milano AD, De Carlo M, Mecozzi G, D'Alfonso A, Scioti G, Nardi C, et al. Clinical outcome in patients with $19-\mathrm{mm}$ and $21-\mathrm{mm}$ St. Jude aortic prostheses: comparison at long-term follow-up. Ann Thorac Surg. 2002;73:37-43.

8. Blais C, Dumesnil JG, Baillot R, Simard S, Doyle D, Pibarot P. Impact of prosthesis-patient mismatch on short-term mortality after aortic valve replacement. Circulation. 2003;108:983-8.

9. Mohty-Euhahidi D, Girard SE, Malouf JF, Connolly HM, Balley KR, Sarano ME, et al. Impact of prosthesis-patient mismatch on long-term survival in patients with small St Jude mechanical prosthesis in the aortic position. Circulation. 2006;113:420-6.

10. Ruel M, Rubens FD, Masters RG, Pipe AL, Bedard P, Hendry PJ, et al. Late incidence and predictors of persistent or recurrent heart failure in patients with aortic prosthetic valves. J Thorac Cardiovas Surg. 2004;127:149-59.

11. Tasca G, Brunelli F, Cirillo M, DallaTomba M, Mhagna Z, Troise G, et al. Impact of valve prosthesis-patient mismatch on left ventricular mass regression following aortic valve replacement. Ann Thorac Surg. 2005;79:505-10.

12. Botzenhardt F, Eichinger WB, Bleiziffer S, Guenzinger R, Wagner IM, Bauernschmitt R, et al. Hemodynamic comparison of bioprostheses for complete supra-annular position in patients with small aortic annulus. J Am Coll Cardiol. 2005;45:2054-60.

13. Tasca G, Brunelli F, Cirillo M, Dalla Tomba M, Mhagna Z, Troise G, et al. Impact of the improvement of valve area achieved with aortic valve replacement on the regression of left ventricular hypertrophy in patients with pure aortic stenosis. Ann Thorac Surg. 2005;79:1291-6.

14. Medalion B, Blackstone EH, Lytle BW, White J, Arnold JH, Cosgrove DM. Aortic valve replacement: is valve size important? J Thorac Cardiovasc Surg. 2000;119:963-74.

15. Hanayama N, Christakis GT, Mallidi HR, Joyner CD, Fremes SE, Morgan CD, et al. Patient prosthesis mismatch is rare after aortic valve replacement: valve size may be irrelevant. Ann Thorac Surg. 2002;73: $1822-9$.

16. Blackstone EH, Cosgrove DM, Jamieson WRE, Birkmeyer NJ, Lemmer $\mathrm{JH}$, Jr., Miller DC, et al. Prosthesis size and long-term survival after aortic valve replacement. J Thorac Cardiovasc Surg. 2003;126:783-93.

17. Knez I, Rienmüller R, Maier R, Rehak P, Schröttner B, Mächler H, et al. Left ventricular architecture after valve replacement due to critical aortic stenosis: an approach to dis-/qualify the myth of valve prosthesis-patient mismatch? Eur J Cardiothorac Surg. 2001;19:797805 .
18. Freed DH, Tam JW, Moon MC, Harding GE, Ahmad E, Pascoe EA. Nineteen-millimeter prosthetic aortic valves allow normalization of left ventricular mass in elderly women. Ann Thorac Surg. 2002;74: 2022-5.

19. Koch CG, Khandwala F, Estafanous FG, Loop FD, Blackstone EH. Impact of prosthesis-patient size on functional recovery after aortic valve replacement. Circulation. 2005;111:3221-9.

20. Rahimtoola SH. The problem of valve prosthesis-patient mismatch. Circulation. 1978;58:20-4.

21. Dumesnil JG, Honos GN, Lemieux M, Beauchemin J. Validation and applications of indexed aortic prosthetic valve areas calculated by Doppler echocardiography. J Am Coll Cardiol. 1990;16:637-43.

22. Dumesnil JG, Yoganathan AP. Valve prosthesis hemodynamics and the problem of high transprosthetic pressure gradients. Eur J Cardiothorac Surg. 1992;6:S34-8.

23. Muneretto C, Bisleri G, Negri A, Manfredi J. The concept of patientprosthesis mismatch. J Heart Valve Dis. 2004;13:S59-62.

24. Castro LJ, Arcidi JMJ, Fisher AL, Gaudiani VA. Routine enlargement of the small aortic root: a preventive strategy to minimize mismatch. Ann Thorac Surg. 2002;74:31-6.

25. Pibarot P, Dumesnil JG, Cartier PC, Métras J, Lemieux M. Patientprosthesis mismatch can be predicted at the time of operation. Ann Thorac Surg. 2001;71:S265-8.

26. Connolly HM, Oh JK, Schaff HV, Roger VL, Osborn SL, Hodge DO, et al. Severe aortic stenosis with low transvalvular gradient and severe left ventricular dysfunction: result of aortic valve replacement in 52 patients. Circulation. 2000;101:1940-6.

27. Briand M, Dumesnil JG, Kadem L, Tongue AG, Rieu R, Garcia D, et al. Reduced systemic arterial compliance impacts significantly on LV afterload and function in aortic stenosis: implications for diagnosis and treatment. J Am Coll Cardiol. 2005;46:291-8.

28. Botzenhardt F, Eichinger WB, Guenzinger R, Bleiziffer S, Wagner I, Bauernschmitt R, et al. Hemodynamic performance and incidence of patient-prosthesis mismatch of the complete supraannular Perimount Magna bioprosthesis in the aortic position. Thorac Cardiovasc Surg. 2005;53:226-30.

29. Dumesnil JG, LeBlanc MH, Cartier P, Métras J, Desaulniers D, Doyle $\mathrm{D}$, et al. Distinctive hemodynamic features of the Freestyle aortic bioprothesis as compared with stented bioprosthesis. Ann Thorac Surg. 1998;66:S130-3.

30. Bach DS, Sakwa MP, Goldbach M, Petracek MR, Emery RW, Mohr FW. Hemodynamics and early clinical performance of the St. Jude Medical Regent mechanical aortic valve. Ann Thorac Surg. 2002;74: 2003-9.

31. Chambers J, Ely JL. Early postoperative echocardiographic hemodynamic performance of the On-X prosthetic heart valve: a multicenter study. J Heart Valve Dis. 1998;7:569-73.

32. Laforest I, Dumesnil JG, Briand M, Cartier PC, Pibarot P. Hemodynamic performance at rest and during exercise after aortic valve replacement: comparison of pulmonary autografts versus aortic homografts Circulation. 2002;106[suppl I]:I57-62. 